\title{
Antibody Treatment Promotes Compensation for Human Cytomegalovirus-Induced Pathogenesis and a Hypoxia-Like Condition in Placentas with Congenital Infection
}

\author{
Ekaterina Maidji, ${ }^{*}$ Giovanni Nigro, ${ }^{\dagger}$ \\ Takako Tabata, ${ }^{*}$ Susan McDonagh, ${ }^{*}$ \\ Naoki Nozawa, ${ }^{*}$ Stephen Shiboski, ${ }^{\neq}$ \\ Stefania Muci, ${ }^{\dagger}$ Maurizio M. Anceschi, ${ }^{\S}$ \\ Natali Aziz," Stuart P. Adler," and Lenore Pereira* \\ From the Department of Cell and Tissue Biology,* School of \\ Dentistry, and the Department of Epidemiology and Biostatistics, ${ }^{\ddagger}$ \\ School of Medicine, University of California-San Francisco, San \\ Francisco, California; the Department of Pediatrics, ${ }^{\dagger}$ University of \\ L'Aquila, L'Aquila, Italy; the Department of Obstetrics, \\ Gynecology and Perinatology, ${ }^{\varsigma}$ La Sapienza University of Rome, \\ Rome, Italy; the Department of Obstetrics and Gynecology, "ा \\ School of Medicine, Stanford University, Stanford, California; \\ and the Department of Pediatrics," Medical College of Virginia \\ Campus, Virginia Commonwealth University, Richmond, Virginia
}

Human cytomegalovirus (HCMV) is the major viral cause of birth defects worldwide. Affected infants can have temporary symptoms that resolve soon after birth, such as growth restriction, and permanent disabilities, including neurological impairment. Passive immunization of pregnant women with primary HCMV infection is a promising treatment to prevent congenital disease. To understand the effects of sustained viral replication on the placenta and passive transfer of protective antibodies, we performed immunohistological analysis of placental specimens from women with untreated congenital infection, HCMV-specific hyperimmune globulin treatment, and uninfected controls. In untreated infection, viral replication proteins were found in trophoblasts and endothelial cells of chorionic villi and uterine arteries. Associated damage included extensive fibrinoid deposits, fibrosis, avascular villi, and edema, which could impair placental functions. Vascular endothelial growth factor and its receptor fms-like tyrosine kinase 1 (Flt1) were up-regulated, and amniotic fluid contained elevated levels of soluble Flt1 (sFlt1), an antiangiogenic protein, relative to placental growth factor. With hyperimmune globulin treatment, placentas appeared uninfected, vascular endothelial growth factor and Flt1 expression was reduced, and sFlt1 levels in amniotic fluid were lower. An increase in the number of chorionic villi and blood vessels over that in controls suggested compensatory development for a hypoxia-like condition. Taken together the results indicate that antibody treatment can suppress HCMV replication and prevent placental dysfunction, thus improving fetal outcome. (AmJ Pathol 2010, 177:1298-1310; DOI: 10.2353/ajpath.2010.091210)

Human cytomegalovirus (HCMV) is the most important viral cause of congenital infection, resulting in developmental disabilities ${ }^{1,2}$ and other neurological problems that are as frequent as those from Down syndrome, fetal alcohol syndrome, and neural tube defects. ${ }^{3}$ Each year approximately 40,000 infants in the United States are born with congenital HCMV infection. Of these, 400 will die in childhood and 8000 will have permanent disabilities, including mental retardation, neuromotor abnormalities, and progressive sensorineuronal deafness. ${ }^{4,5}$ The prevalence of HCMV seropositivity is estimated to be 50 to $70 \%$ of the U.S. population. ${ }^{6,7}$ Women with primary HCMV infection and viremia often have very low-avidity IgG, which is associated with symptomatic congenital infection ${ }^{8-10}$ and approximately $40 \%$ transmit infection to the fetus in the first trimester. ${ }^{11}$ In contrast, women with

Supported by grants from the National Institutes of Health (Al46657, Al53782, and Al073752 to L.P.), Sanofi-Pasteur and the Thrasher Research Fund (02821-7 to L.P.). N.N. was supported by a Scholarship Award from the Japan Herpesvirus Infections Forum.

Accepted for publication April 29, 2010.

None of the authors declare any relevant financial relationships.

Address reprint requests to Lenore Pereira, Ph.D., Department of Cell and Tissue Biology, School of Dentistry, University of CaliforniaSan Francisco, San Francisco, CA 94143. E-mail: lenore.pereira@ ucsf.edu. 
immunity to HCMV before conception rarely deliver infants with symptomatic infection. ${ }^{6}$ Symptomatic infants (25\% of those born with congenital infection) can have both temporary symptoms and permanent birth defects. ${ }^{4}$ Symptoms such as intrauterine growth restriction (IUGR) and hepatosplenomegaly, which originate in insufficient placental functions, improve after birth. In contrast, viral replication in the fetal brain may cause neurological damage and permanent disabilities. ${ }^{12}$

A critical hurdle in pregnancy maintenance is the embryo's acquisition of a supply of maternal blood. ${ }^{13} \mathrm{Cy}$ totrophoblasts, which are specialized epithelial cells of the placenta, perform the mechanics of this process. These cells follow two tightly regulated pathways that give rise to the differentiated cytotrophoblasts in anchoring and floating villi. In floating villi, which are attached at only one end to the tree-like fetal portion of the placenta, villous cytotrophoblasts differentiate by fusing with the multinucleated syncytiotrophoblasts that are in direct contact with maternal blood and participate in nutrient, waste, and gas exchange. In anchoring villi, which are attached at one end to the fetal portion of the placenta and at the other end to the uterus, a subpopulation of cytotrophoblasts aggregate into cell columns and invade the maternal decidua. Cell column cytotrophoblasts include undifferentiated proliferating cells and differentiated invasive cells. A subset of differentiated cells invades the first third of the myometrium (interstitial invasion) and breaches portions of the maternal arterioles that span these regions (endovascular invasion). By midgestation, endovascular cytotrophoblasts, which have completed an epithelial-to-endothelial transition, replace the endothelial cell lining and result in a hybrid vasculature composed of fetal and maternal cells. Cytotrophoblast proliferation and differentiation are strictly regulated by oxygen tension. ${ }^{14,15}$ The cells also express substances that influence vasculogenesis and angiogenesis, including vascular endothelial growth factor family ligands vascular endothelial growth factor (VEGF), placental growth factor (PIGF) and receptors VEGF receptor 1 (Flt1) and VEGF receptor 2. ${ }^{16,17}$ VEGF is expressed downstream in the transcriptional network that regulates cellular responses to oxygen tension, and its expression changes as cytotrophoblasts differentiate. ${ }^{14,15,18}$ By midgestation, when the uterine-placental vasculature has been established, normoxic conditions prevail in healthy pregnancies and VEGF expression declines.

Studies of early gestation placentas showed that determinants of placental infection include the avidity of HCMV-specific antibodies in the circulation and virion receptors expressed on cytotrophoblasts. In the pregnant uterus, initial infection in the uterine vasculature spreads to invasive cytotrophoblasts that remodel the arterioles. ${ }^{19-21}$ In the adjacent placenta, syncytiotrophoblasts internalize IgG-virion complexes that are transcytosed by the neonatal Fc receptor. ${ }^{20,22}$ Syncytiotrophoblasts of placentas from women strongly seropositive for HCMV (ie, with high-avidity $\lg G$ ) contain virion structural proteins and DNA. ${ }^{20,23}$ In the presence of low-avidity IgG, HCMV replicates in underlying cytotrophoblasts, causing focal infection that spreads to the villous stroma and fetal capillaries. ${ }^{20,22,24}$ Productive infection is regulated by proteins that serve as virion receptors, epidermal growth factor receptor and integrin $\alpha \mathrm{v}$, expressed on villous cytotrophoblast progenitors, and integrins $\alpha 1 \beta 1$ and $\alpha \vee \beta 3$, induced on invasive cells. ${ }^{25}$ Infected cytotrophoblasts impair differentiation, down-regulate key integrins and adhesion molecules, and produce cmvlL-10, a viral cytokine that reduces matrix metalloproteinase 9 activity and degradation of the extracellular matrix. ${ }^{26}$ In blood vessels of chorionic villi, infected endothelial cells up-regulate integrin $\alpha \vee \beta 6$, which activates transforming growth factor- $\beta$ and increases extracellular matrix deposition. ${ }^{27}$ Based on the profound dysregulation observed in vitro, HCMV replication at the uterine-placental interface could impair vascular remodeling and cause fibrosis, occluding blood flow and further reducing exchange between the maternal and fetal circulation.

It was reported that hyperimmune globulin (HIG) containing HCMV-specific, high-avidity antibodies infused into the maternal bloodstream after primary infection significantly reduced virus transmission and congenital disease. ${ }^{28} \mathrm{IgG}$ avidity in circulation increased after infusion and was higher among treated mothers than among untreated mothers at delivery. Ultrasound analysis showed that untreated placentas were thicker than those of women receiving HIG treatment. ${ }^{29}$ To understand the underlying basis for the differences, we performed semiquantitative immunohistological analysis of placentas and measured hypoxia-related factors from women with primary HCMV infection during gestation who did or did not receive HIG treatment to prevent congenital disease.

\section{Materials and Methods}

\section{Study Group}

Placental biopsy specimens and amniotic fluid were described previously. ${ }^{28,30}$ Approval to obtain placentas from Moffitt Hospital was acquired from the Institutional Review Board of the University of California-San Francisco. Primary infection was identified by seroconversion in previously HCMV-seronegative women or by detection of HCMV IgM and very low levels of IgG with low avidity $(\leq 25 \%)$. Congenital infection was confirmed by isolating the virus or detecting viral DNA in fetal urine or saliva by real-time PCR (Amplimedical-Bioline, Turin, Italy). Symptomatic disease included neurological involvement with microcephaly, periventricular calcifications, cerebral dysplasias, chorioretinitis, and auditory impairment. Head and abdominal circumferences less than the 10th percentile for fetuses of a similar age were evidence of IUGR. HCMV disease at $\geq 2$ years manifested as mental and/or motor retardation $(I Q<70)$ and auditory or visual impairment. HCMV-specific IgG, IgM, and IgG avidity was evaluated by enzyme immunoassays (ELISAs) from Radim (Pomezia, Italy) and Diasorin (Saluggia, Italy). The HIG treatment group consisted of women who received monthly treatment with HIG within 6 weeks of seroconversion, from diagnosis of infection until delivery. The 
control group consisted of HCMV-seronegative pregnant women.

\section{Placental Biopsy Specimens}

Biopsy specimens from 26 placentas from women with untreated congenital CMV infection, women receiving HIG prevention, and healthy controls were selected for analysis based on following criteria: i) primary infection occurred in first trimester of pregnancy, ii) consent to receive HIG was obtained, iii) treatment was begun soon after seroconversion, and iv) women were nonsmokers during pregnancy. These criteria were met in 18 women with untreated infection, 3 women receiving HIG treatment, and 5 controls. The numbers of placentas used in our analyses represented the total number available for study. Biopsy specimens (two to five each) were taken from different sites in the placenta center, fixed in 10\% formalin, and embedded in paraffin. Serial $5-\mu \mathrm{m}$-thick tissue sections of the paraffin-embedded biopsy specimens were used in all experiments.

\section{Microscopic Evaluation of Pathology}

Tissue sections were deparaffinized in xylene and rehydrated in graded alcohols and stained with H\&E. Tissue morphology was evaluated without group identifiers and reviewed independently by two investigators blinded to the clinical outcome (E.M. and L.P.) with assistance from a clinical pathologist. Biopsy specimens were examined for histological abnormalities associated with congenital HCMV infection, hypoxia-associated injury, and compensatory development (described in Results). Immunostaining was performed for HCMV proteins and specific hypoxia-induced cellular proteins. Each manifestation of pathology was rated from 1 to 3 based on frequency of appearance within a biopsy specimen.

\section{Immunohistochemistry}

Tissue sections were deparaffinized in xylene and rehydrated in graded alcohols. Endogenous peroxidase was quenched with $3 \% \mathrm{H}_{2} \mathrm{O}_{2}$ in methanol for 10 minutes. $\mathrm{HCMV}$ antigens were retrieved by heating tissue slides in $10 \mathrm{mmol} / \mathrm{L}$ sodium citrate, $\mathrm{pH}$ 6.0, for the detection of cytokeratin 7, CD31 (PECAM-1), CD34, CD68, VEGF, and Flt1. Nonspecific binding was reduced by incubation in PBS containing $1 \%$ bovine serum albumin and $5 \%$ normal host serum of secondary antibody. We used primary rabbit polyclonal antibodies to von Willebrand factor (Novocastra Laboratories, Newcastle, UK), VEGF (A20, Santa Cruz Biotechnology, Santa Cruz, CA), PECAM-1 (H-300, Santa Cruz Biotechnology), and Flt1 (Abcam, Cambridge, MA). Mouse monoclonal antibodies were CD68 (clone KP1, Zymed Laboratories, South San Francisco, CA), CD34 (BD Biosciences Pharmingen, San Diego, CA), cytokeratin 7 (clone OV-TL 12/30; Dako, Carpinteria, CA), and HCMV immediate early 1 and 2 proteins (UL123) and DNA-binding protein (UL44) (clones CCH2+DDG9, Dako). HCMV proteins were de- tected with high-pH Target Retrieval Solution (Dako). Primary antibodies were incubated overnight at $4^{\circ} \mathrm{C}$ in a humidified chamber. Labeling with secondary antibody was performed using two methods: the biotin/avidin system (Vectastain ABC kit, Vector Laboratories, Burlingame, CA) and direct labeling using Fab fragments of secondary antibodies (PicTure-Double Staining Kit, Invitrogen, Carlsbad, CA). Immunolabeling with mouse IgG was developed using a diaminobenzidine (DAB) substrate kit (Vector Laboratories). For double immunolabeling, goat anti-mouse IgG-horseradish peroxidase was used with DAB to produce one stain (brown) and goat anti-rabbit IgG-alkaline phosphatase was used with FastRed to produce a second stain (red). Counterstaining was done with hematoxylin (Vector Laboratories). Specificity of each immunohistochemical reaction was verified by using nonimmune rabbit or mouse IgG (Vector Laboratories) as the primary antibody and secondary antibody labeling by the two methods described above. Immunostaining was reproduced from 3 to 10 times. Images were obtained using a Nikon Eclipse 50i microscope.

\section{Quantification of Chorionic Villi and Blood Vessels}

Cytokeratin 7-stained tissue sections were used to quantify chorionic villi. Two sections taken at different levels of the tissue block were analyzed from each placenta. Three to five placentas per group were examined. One hundred to 200 microscopic fields were scanned at $\times 200$ magnification, and the number of villi per $\mathrm{mm}^{2}$ was counted. Placental sections double-stained for CD34 and CD31 were used to count the blood vessels. Tissue sections were scanned at $\times 400$ magnification, and the number of blood vessels per villus was counted for 100 villi.

\section{Image Analysis}

Semiquantitative image analysis of VEGF and Flt1 immunostaining was performed using DAB-labeled (see above) tissue sections. Five to six images ( $\times 200$ magnification) from randomly selected areas were obtained using a Nikon Eclipse 50i microscope. Illumination conditions of the bright-field optics and camera exposure were maintained constant throughout acquisition of all images. Background correction was performed before digital acquisition. ImageJ (National Institute of Health, Bethesda, MD) was used to perform semiquantitative analysis of the digitalized images. Conventional brightfield RGB color images were split and the blue component (greater contrast DAB staining) was selected as described previously ${ }^{31}$ and used for further analysis. The mean staining intensity (mean gray value of the pixels in the selection) was measured for each image as described previously. ${ }^{32,33}$ In brief, the mean gray value was measured as the sum of the gray values of all of the pixels in the selection divided by the number of pixels. Because the darker staining correlates with the lower gray value, the gray-scale images were inverted to make the staining 

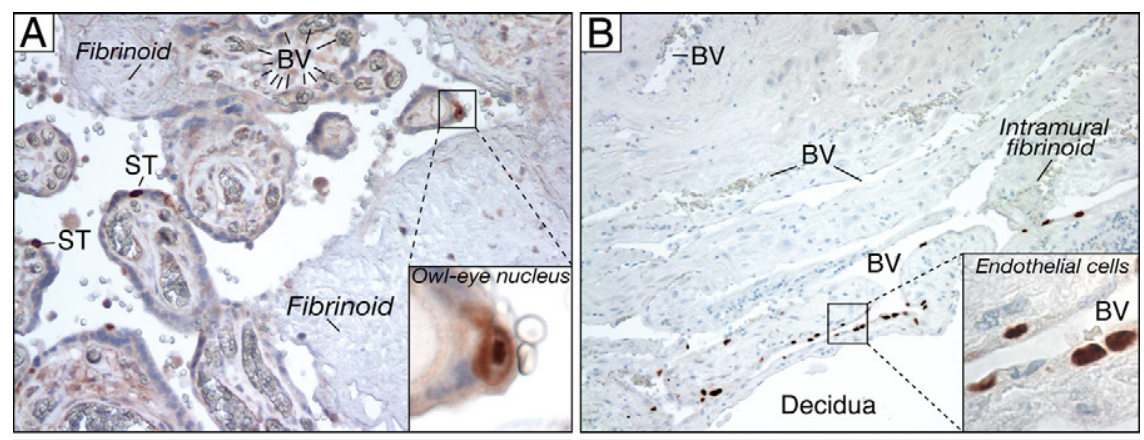

Figure 1. HCMV replication proteins found in untreated congenitally infected placentas $(n=$ 18). Paraffin-embedded tissue sections immunostained for HCMV pUL123 and UL44; original magnification, $\times 100$. Nuclei were counterstained with hematoxylin. A: Owl-eye nucleus of a cytomegalic cell (inset, original magnification, $\times 400$ ) in close proximity to a large fibrinoid. Proximal villi contain infected syncytiotrophoblasts (brown nuclei) and numerous congested capillaries. B: Infected endothelial cells in a uterine artery (inset, original magnification, $\times 400$ ) near an intramural fibrinoid (thrombi). C: HCMV-infected trophoblasts (inset, original magnification, $\times 200$ ) surround the villus core of adjacent chorionic villi. D: Fetal leukocytes in blood vessels of the villus core contain HCMVinfected-cell proteins (inset, original magnification, $\times 200$ ). BV, blood vessel; ST, syncytiotrophoblasts; VC, villus core.

intensity more intuitive: increased VEGF or Flt1 staining intensity correlated with greater gray value.

\section{Quantification of Angiogenic Factors}

Amniotic fluid was centrifuged, aliquoted, and stored at $-70^{\circ} \mathrm{C}$. Soluble (s) Flt1 and PIGF concentrations were measured with a commercial quantitative sandwich ELISA (Quantikine, R\&D Systems, Minneapolis, MN). Free VEGF was detected using a quantitative sandwich ELISA (ChemiKine, catalog no. CYT214, Chemicon International, Temecula, CA). The sensitivity of the assays was as follows: sFlt1, $3.5 \mathrm{pg} / \mathrm{ml}$; PIGF, $7 \mathrm{pg} / \mathrm{ml}$; and VEGF, $26.6 \mathrm{pg} / \mathrm{ml}$. Interassay and intra-assay coefficients of variation were 3 to $10 \%$. All measurements were performed in duplicate by investigators blinded to clinical information. The sFlt1/PIGF ratio, used as an indicator of balanced angiogenic factors, was computed by using the formula, $\log _{10}[\mathrm{sFIt} 1 / \mathrm{PIGF} \times 100]^{34,35}$

\section{Statistical Analysis}

Quantitative data for statistical analysis of the number of chorionic villi and blood vessels were obtained by screening 100 to 200 microscopic fields per slide for three to four placentas per group. The average counts of the villi in placentas from the untreated and HIG treatment groups were compared with those in uninfected controls by using Poisson regression analysis. The analyses were controlled for the fact that each individual contributed multiple measurements. sFlt1 and PIGF concentrations in amniotic fluid were summarized using group-specific means and 95\% confidence intervals, and the results are displayed graphically. Comparisons between groups were performed using one-way analysis of variance with Bonferroni correction of $P$ values for multiple compari- sons. To account for possible nonnormality of outcome distributions and for the relatively small sample size, we performed additional analyses using log-transformed outcomes and basing confidence intervals and $P$ values on Bootstrap resampling using 1000 replications. These additional analyses did not alter any findings of significance compared with the results based on the assumption of normality, so only the latter results are reported.

\section{Results}

\section{Viral Replication and Histopathological Changes in Infected Placentas}

In the first set of experiments, we examined biopsy specimens of placentas from women with untreated congenital HCMV infection or after HIG treatment for patterns of viral replication by immunostaining and histopathology. Detection of infected foci required examination of numerous tissue sections cut from different levels within the specimen blocks. Analysis of placentas from the untreated infected group showed viral replication proteins immunostained in cytomegalic cells, trophoblasts, and endothelial cells (Figure 1). Focal patterns of infected cells were widely scattered throughout the chorionic villi, and cytomegalic cells with owl-eye nuclear inclusions were infrequent (Figure 1A). Immunostaining for HCMV proteins revealed positive cells, indicating viral replication in endothelial cells in the uterine vasculature (Figure 1B). Occasionally, we observed an intramural fibrinoid within a uterine artery, considered a histological feature of HCMV infection. ${ }^{36}$ In the placenta, clusters of infected trophoblasts were found in neighboring chorionic villi (Figure 1C). Sometimes, viral replication proteins were observed in fetal leukocytes and endothelial cells of vil- 

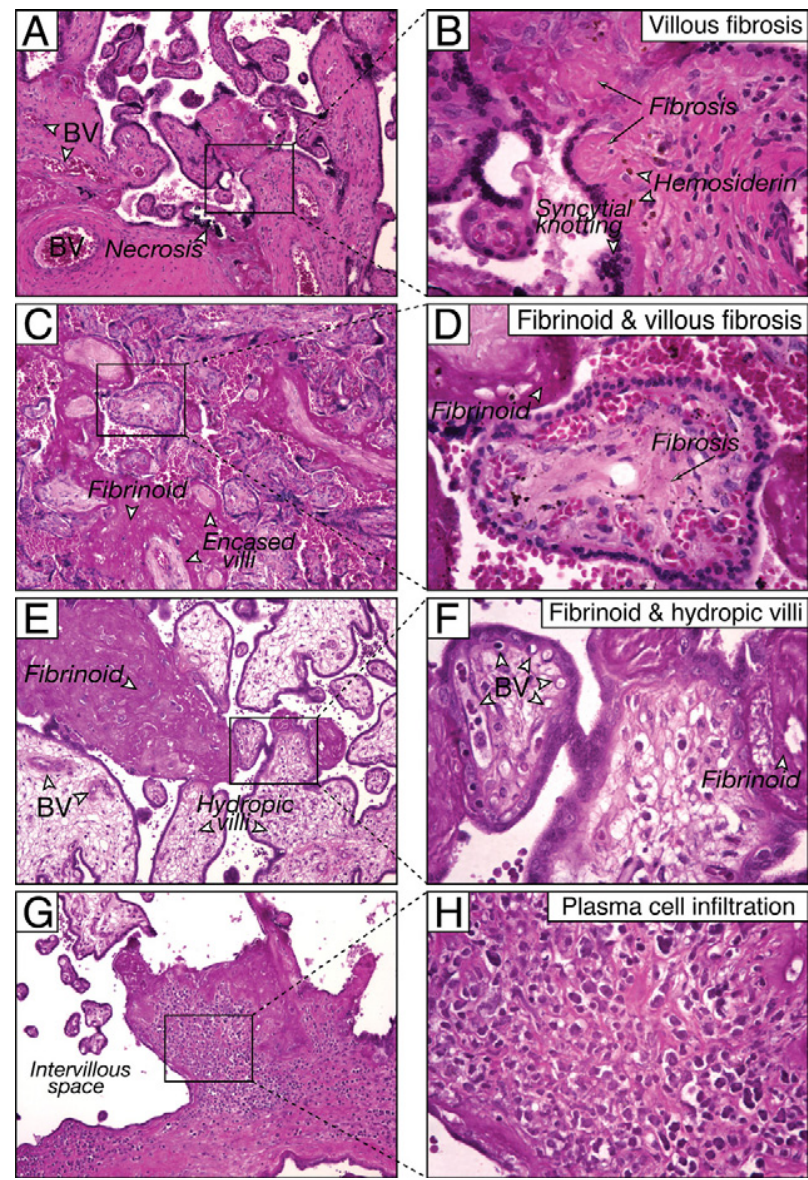

Figure 2. Histopathological changes in untreated HCMV-infected placentas. $\mathbf{A}$ and B: Fibrotic villi with necrosis, calcification, and hemosiderin deposits $\mathbf{C}$ and D: Fibrin-encased avascular villi and fibrosis in the villus core. $\mathbf{E}$ and F: Area of fibrin deposition surrounded by severely hydropic villi. $\mathbf{G}$ and $\mathbf{H}$ : Chorionic villitis with plasma cell infiltration. H\&E stain. Original magnification: $\times 100(\mathbf{A}-\mathbf{H}) ; \times 400$ (insets). BV, blood vessel

lous capillaries (Figure 1D). Notably, after exhaustive examination of numerous sections, expression of HCMV proteins was not detected in placentas from the HIG treatment group $(n=3)$ or uninfected controls $(n=5)$ (data not shown).
Histological analysis showed that pathological changes were found only in placentas with untreated congenital HCMV infection. Typical damage is shown in sections stained with H\&E (Figure 2). Necrosis and extensive stromal fibrosis were present in villi that contained many hemosiderin-laden macrophages, indicating infarcted blood vessels and long-term hemolysis (Figure 2, A-D). Syncytial knotting was frequently observed (Figure 2B). Large areas contained many chorionic villi that were encased in fibrin and had few or no blood vessels (Figure 2, C and D). Large areas of fibrinoid deposition were often surrounded by hydropic villi with compressed capillaries at the periphery (Figure 2, E and F). The presence of severely hydropic villi suggested inflammation. We occasionally detected villi composed almost entirely of plasma cells (chorionic villitis) (Figure 2, $G$ and $H$ ). In marked contrast, pathological changes from viral replication were absent from the HIG treatment group, except for small perivillous fibrinoid plaques (data not shown).

Total histopathology scores were calculated for placentas with untreated infection, with or without fetal transmission, or HIG treatment and controls on the basis of two criteria i) Infection-associated pathology included detection of HCMV replication proteins, necrosis, calcification, fibrosis, and large fibrinoids as well as inflammation indicated by plasma cells, hemosiderin-laden macrophages, leukocytic infiltration, and edematous villi. ii) Hypoxiaassociated pathology included extensive syncytial knotting (Tenny-Parker changes), dilated and congested blood vessels, and villi that were largely avascular or encased in fibrinoids. Increased villous microvascular density (ie, hypoxic hypercapillarization) and increased numbers of chorionic villi indicated compensatory development. Each pathological feature was rated on a scale of 1 to 3 according to the frequency of defects and compensation observed within a biopsy specimen, and then a cumulative score was obtained for each specimen. Table 1 summarizes the histopathological results.

Values quantifying changes related to infection and hypoxia were comparable in untreated congenital infection with seroconversion in the first trimester $(16 \pm 1.7$ and $16 \pm 3.6$, respectively) and the second trimester

Table 1. Semiquantitative Analysis of HCMV-Induced Pathology, Hypoxic Conditions, and Compensatory Development in Placentas from Congenital Infection

\begin{tabular}{|c|c|c|c|c|c|}
\hline \multirow[b]{3}{*}{ Placental pathological features } & \multicolumn{3}{|c|}{ Untreated congenital HCMV infection } & \multirow{3}{*}{$\begin{array}{l}\text { HIG treatment } \\
\text { (no transmission): } \\
\text { first trimester }\end{array}$} & \multirow[b]{3}{*}{$\begin{array}{l}\text { Uninfected } \\
\text { controls }\end{array}$} \\
\hline & \multicolumn{2}{|c|}{ Fetal transmission } & \multirow[b]{2}{*}{$\begin{array}{l}\text { No transmission: } \\
\text { first trimester }\end{array}$} & & \\
\hline & $\begin{array}{c}\text { First } \\
\text { trimester }\end{array}$ & $\begin{array}{l}\text { Second } \\
\text { trimester }\end{array}$ & & & \\
\hline Infection-associated* & $16 \pm 1.7$ & $14 \pm 2.5$ & $7 \pm 2.5$ & $5 \pm 1.2$ & $4 \pm 1.5$ \\
\hline Hypoxia-associated $^{\dagger}$ & $16 \pm 3.6$ & $13 \pm 1.5$ & $13 \pm 3$ & $12 \pm 0.6$ & $5 \pm 0.6$ \\
\hline Total & $1.32 \pm 5.3^{\ddagger \S}$ & $28 \pm 2.3^{\S}$ & $20 \pm 4.9$ & $17 \pm 1$ & $10 \pm 2.1$ \\
\hline
\end{tabular}

Statistical analysis are described in Materials and Methods. Pathological features were rated on a scale of 1 to 3 by frequency on 100 to 200 microscopic fields ( $\times 200$ magnification) for three placentas per group.

*Infection-associated changes included HCMV replication proteins and damage from necrosis, calcification, fibrosis, large fibrinoids, inflammation with plasma cells, hemosiderin-laden macrophages, leukocytic infiltration, and edematous villi. ${ }^{1-3}$

${ }^{\dagger}$ Hypoxia-associated changes included syncytial knotting (Tenny-Parker changes), dilated and congested blood vessels, and avascular fibrinoidencased villi, increased microvascular density (hypoxic hypercapillarization), and villous density. ${ }^{1}$

FValues compared with uninfected controls $(P<0.01)$.

$\S$ Values compared with HIG treatment $(P<0.01)$. 
(14 \pm 2.5 and $13 \pm 1.5$, respectively). All values for infection- and hypoxia-associated changes were higher than values obtained for controls $(4 \pm 1.5$ and $5 \pm 0.6$, respectively). Interestingly, values for infection-associated changes were lower than those for hypoxia-associated changes in untreated infection without virus transmission ( $7 \pm 2.5$ and $13 \pm 3$, respectively) and in the $\mathrm{HIG}$ treatment group without virus transmission $(5 \pm 1.2$ and $12 \pm 0.6$, respectively). Notably, hypoxia-associated values in all congenitally infected placentas, with or without virus transmission, and in the HIG treatment group were consistently higher than those in controls.

Comparable total histopathology scores were found for untreated congenital $\mathrm{HCMV}$ infection with seroconversion in the first trimester $(32 \pm 5.3)$ and the second trimester (28 \pm 2.3$)$. The scores for untreated congenital infection with seroconversion in the first trimester were significantly higher than those in the HIG treatment group $(P=0.007)$ and in controls $(P<0.001)$.

The scores for untreated congenital infection with seroconversion in the second trimester were significantly higher than those in controls $(P=0.002)$ but only marginally significant compared with those in the HIG treatment group $(P=0.054)$. Taken together, the results indicate that placentas with untreated congenital infection in the first and second trimesters sustain considerable damage from viral replication and hypoxia combined.

\section{Compensatory Development in Congenitally Infected Placentas}

Focal infection in the uterine vasculature could compromise cytotrophoblast remodeling of the arterioles and reduce maternal blood flow to the developing placenta, leading to hypoxia. ${ }^{20}$ Compensatory development, which manifests as increased numbers of chorionic villi and capillaries in the villus core, is found in placentas with physiological hypoxia from high altitudes ${ }^{37}$ and in placentas from women who smoked during gestation. ${ }^{38,39}$

Preliminary analysis of H\&E-stained tissue sections revealed the presence of many immature chorionic villi in congenitally infected placentas compared with controls (data not shown). We next counted the number of villi in samples immunostained for cytotrophoblasts using anticytokeratin-7 antibody (Figure 3, A-C). Increased numbers of chorionic villi were found in untreated congenitally infected placentas (Figure 3B), and there were dramatic increases with $\mathrm{HIG}$ treatment (Figure $3 \mathrm{C}$ ) compared with controls (Figure 3A). Average villi counts in the untreated infected group were 1.4 times higher than those in the controls $(P=0.06)$ (Figure 3D). The average villi count in the HIG treatment group was 2.1 times higher than that in controls $(P=0.003)$. The results indicate that untreated congenital infection leads to villous amplification that increases significantly with HIG treatment (Figure 3D).

To count the number of capillaries in the villus core, we immunostained placentas for proteins that are heteroge-
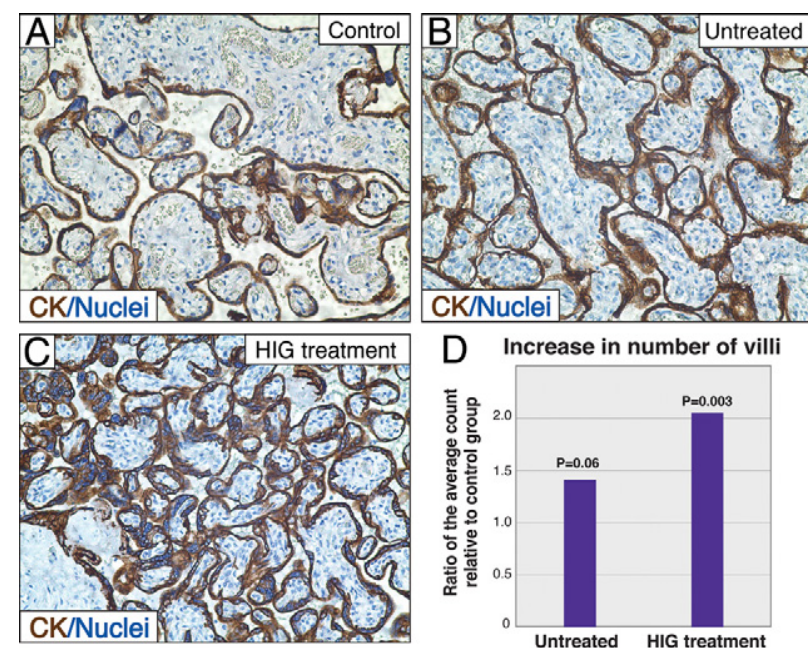

Figure 3. Significant increase in the number of chorionic villi in placentas in the HIG treatment group. Cross-sections of paraffin-embedded placentas were immunostained for trophoblasts with anti-cytokeratin-7 antibody. Nuclei were counterstained with hematoxylin. Original magnification, $\times 200$ The number of villi per $\mathrm{mm}^{2}$ was counted (three to four placentas/group, 100 to 200 microscopic fields; original magnification $\times 200$ ). Representative placentas are from control (A), untreated congenital HCMV infection (B), and HIG treatment $(\mathbf{C})$ groups. D: Graph showing the ratios of average counts relative to controls using Poisson regression.

neously expressed on endothelial cells in different vascular beds and small capillaries. CD34 expression is strong on capillaries, CD31 predominates on pulmonary endothelial cells, and von Willebrand factor varies. ${ }^{40}$ We detected CD31 in all blood vessels, including small capillaries in placentas from controls (Figure 4A), untreated infected placentas (Figure 4, B and C), and HIG-treated placentas (Figure 4D). Intense CD34 expression was found in blood vessels of control placentas (Figure 4A), but expression was usually absent or weak in untreated (Figure 4, B and C) and HIG-treated (Figure 4D) placentas. Large and medium-sized blood vessels, but not small capillaries, strongly expressed von Willebrand factor (data not shown). We then counted the number of blood vessels per villus in each group. The graph in Figure $4 \mathrm{E}$ presents the ratio of the average number of blood vessels in the untreated infected and HIG treatment groups relative to controls. Average counts in the untreated infection group were 1.8 times higher than those in the controls $(P<0.001)$. Average counts in the HIG treatment group were 1.4 times higher than those in controls $(P=0.02)$ and 1.41 times higher than those in the untreated infection group $(P=0.1)$. Quantitative analysis of chorionic villi and capillaries in the villus core showed that placentas with untreated infection and those with HIG treatment developed significantly more capillaries and villi than did the controls. Taken together, the results suggest that compensation for a hypoxia-like state in congenitally infected placentas includes remodeling of the placenta surface and angiogenesis, developmental changes that would increase the surface area for exchange of substances between the maternal and fetal circulation. 


\section{CD31/CD34/Nuclei}

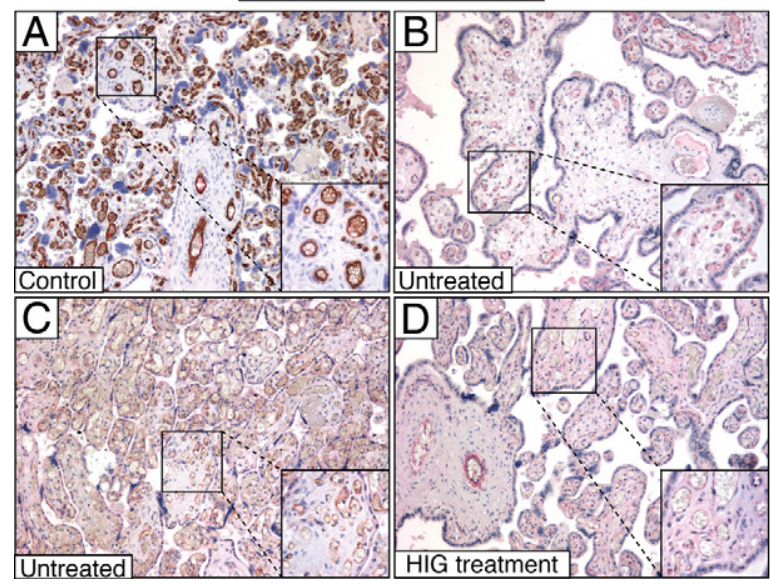

\section{Up-Regulation of Factors Associated with Hypoxia in Congenitally Infected Placentas}

Increased microvascular density in congenitally infected placentas suggested that hypoxic conditions could upregulate the angiogenic factor VEGF and its receptor Flt1, which control vascular development. ${ }^{41,42}$ We next examined VEGF expression in decidua and placentas from control, untreated infection, and HIG treatment groups (Figure 5). Double immunostaining was used to identify syncytiotrophoblasts and villous and invasive cytotropho-

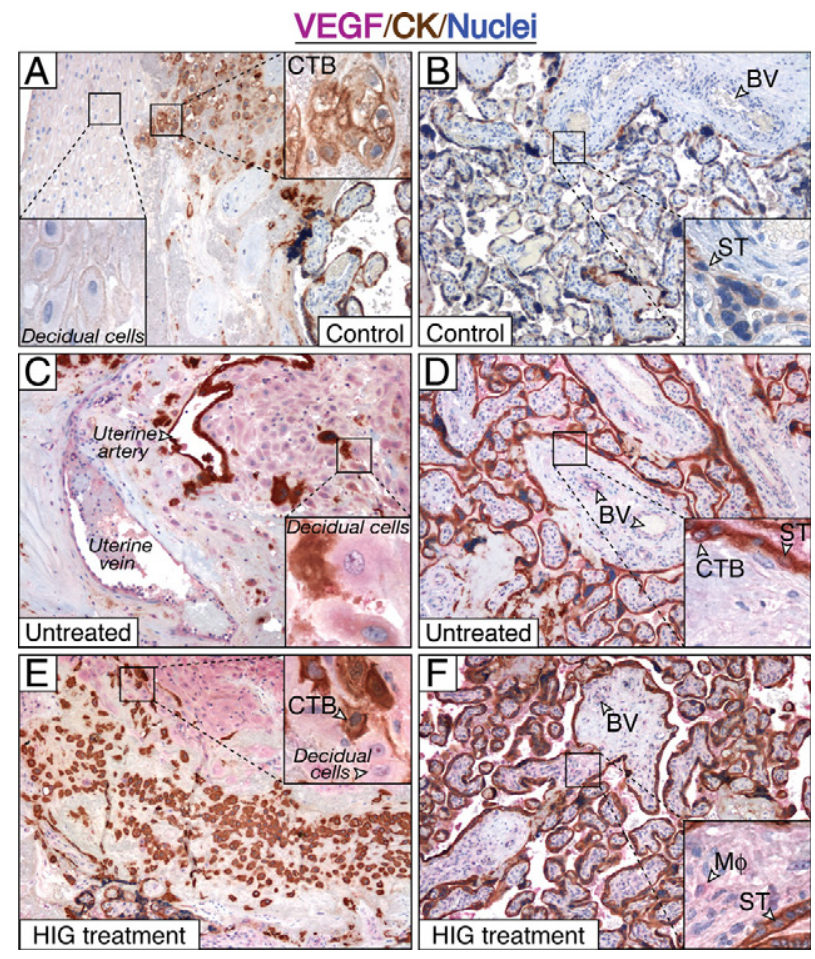

Figure 5. Up-regulated VEGF expression in congenitally infected placentas. Cross-sections of paraffin-embedded placental biopsy specimens were immunostained for VEGF (fuchsia) and cytokeratin 7 (brown). Nuclei were counterstained with hematoxylin. Original magnification: $\times 100(\mathbf{A}-\mathbf{F}) ; \times 400$ (insets). Representative decidua $(\mathbf{A}, \mathbf{C}$, and $\mathbf{E})$ and placentas $(\mathbf{B}, \mathbf{D}$, and $\mathbf{F})$ were from uninfected control (A and $\mathbf{B})$, untreated infection $(\mathbf{C}$ and $\mathbf{D})$, and HIG treatment (E and F) groups. BV, blood vessel; CTB, cytotrophoblasts; ST, syncytiotrophoblasts; $\mathrm{M} \phi$, macrophages.

\section{$E$}

Increase in number of blood vessels

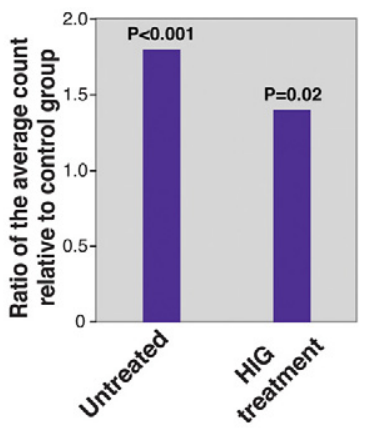

Figure 4. Significant increase in the number of villous blood vessels in congenitally infected placentas. Cross-sections of paraffin-embedded placental biopsy specimens were immunostained for blood vessels with anti-CD34 (brown) and antiCD31 (fuchsia) antibodies. Nuclei were counterstained with hematoxylin. Original magnification, $\times 100$. The number of blood vessels per villus was counted ( 3 to 4 placentas/group, 100 to $200 \mathrm{mi}-$ croscopic fields; insets original magnification, $\times 400$ ). Representative placentas are from uninfected control (A), untreated congenital infection (B and $\mathbf{C}$ ), and HIG treatment (D) groups. E: Graph showing the ratios of average blood vessel counts relative to controls using Poisson regression. blasts, which expressed cytokeratin and coexpressed VEGF. The specificity of each reaction was verified by using nonimmune rabbit lgG as a negative control (data not shown). Control placentas had almost no immunoreactivity to VEGF (Figure 5, A and B). In contrast, untreated infected placentas showed strong VEGF staining localized to decidual cells, syncytiotrophoblasts, cytotrophoblasts, and endothelial cells (Figure 5, C and D). In the HIG treatment group, VEGF was expressed at moderate levels in syncytiotrophoblasts, cytotrophoblasts, and endothelial cells (Figure 5, E and F). Moreover, abundant macrophages in the villus core, especially those proximal to capillaries, expressed VEGF at moderate levels (Figure 5F).

Immunohistological analysis of Flt1 expression in control, untreated infection, and HIG treatment placentas is shown in Figure 6. Double immunostaining was used to identify syncytiotrophoblasts and villous and invasive cytotrophoblasts that coexpressed Flt1. The specificity of each reaction was verified by using nonimmune rabbit IgG as a negative control (data not shown). In controls, strong intracellular Flt1 staining was found in decidual cells and invasive cytotrophoblasts (Figure 6A); syncytiotrophoblasts, villous cytotrophoblasts, and endothelial cells showed moderate intracellular Flt1 expression (Figure 6B), and macrophages showed strong membrane and cytoplasmic staining (Figure 6B, inset). In untreated infection, Flt1 was broadly expressed in a diffuse staining pattern in decidual cells (Figure 6C), syncytiotrophoblasts, cytotrophoblasts, and endothelial cells (Figure 6D). In the HIG treatment group, strong Flt1 staining was found in decidual cells, and weak expression was found in cytotrophoblasts, syncytiotrophoblasts, and endothelial cells (Figure 6, E and F).

Next, we compared the intensity levels of VEGF and Flt1 expression in control, untreated infection, and HIG treatment placentas. Control placentas showed weak VEGF expression: the mean value of staining intensity was 77.1 (Figure 7A). In contrast, untreated infected placentas showed the highest VEGF staining intensity (129.1), followed by the HIG treatment group (114.4). Importantly, we found that all congenitally infected placentas, untreated $(P<0.001)$ and $\mathrm{HIG}$-treated $(P=$ 


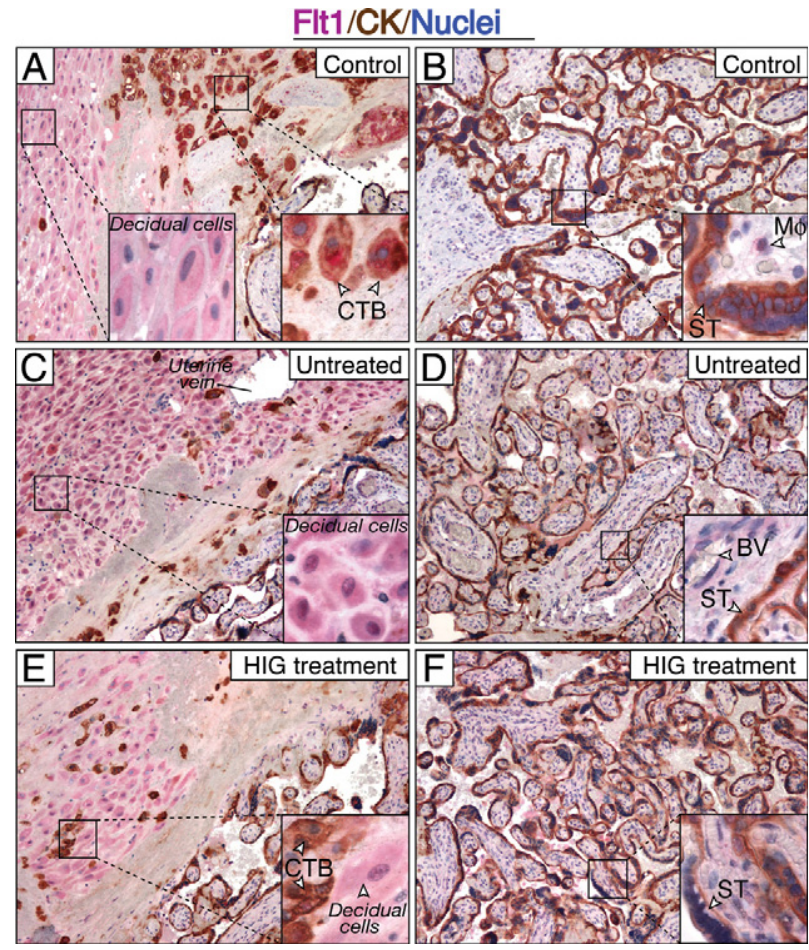

Figure 6. Flt1 expression in congenitally infected placentas. Cross-sections of paraffin-embedded placental biopsy specimens were immunostained for Flt1 (fuchsia) and cytokeratin 7 (brown). Nuclei were counterstained with hematoxylin. Original magnification: $\times 100(\mathbf{A}-\mathbf{F}) ; \times 400$ (insets). Representative decidua $(\mathbf{A}, \mathbf{C}$, and $\mathbf{E})$ and placentas $(\mathbf{B}, \mathbf{D}$, and $\mathbf{F})$ were from control A and $\mathbf{B}$ ), untreated infection $(\mathbf{C}$ and $\mathbf{D})$, and HIG treatment (E and $\mathbf{F})$ groups. BV, blood vessel; CTB, cytotrophoblasts; ST, syncytiotrophoblasts; $\mathrm{M} \phi$, macrophages.

0.018), expressed significantly elevated VEGF levels compared with controls. Although the differences were not significant $(P=0.553)$, a trend to reduced VEGF expression was found in the HIG treatment group compared with the untreated congenital infection group. Quantification of Flt1 immunostaining revealed significant
A

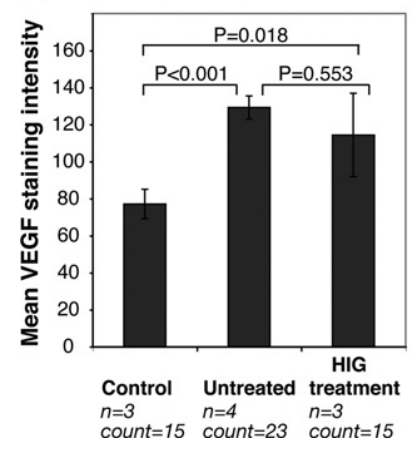

B

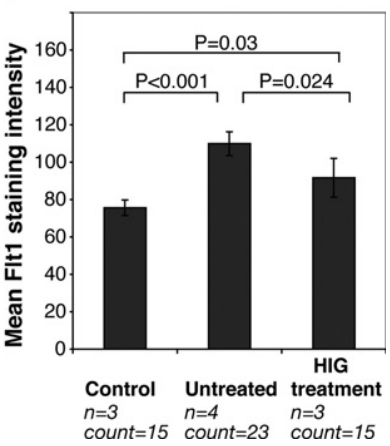

Figure 7. Enhanced VEGF and Flt1 expression in placentas with congenital CMV infection. Levels of VEGF (A) and Flt1 (B) expression were quantified by immunostaining paraffin-embedded placentas from uninfected control $(n=3)$, untreated HCMV infection $(n=4)$, and HIG treatment $(n=4)$ groups. Intensities of DAB-labeled single immunostainings were evaluated using a semiquantitative digital imaging method. ${ }^{31-33}$ The number of digitally quantified counts was 15 for uninfected control, 23 for untreated HCMV infection, and 15 for HIG treatment placentas. Staining intensity was expressed as the mean staining intensity score \pm SEM (bars) and compared between groups using Bonferroni correction of $P$ values for multiple comparisons and Bootstrap resampling using 1000 replications. differences between groups (Figure 7B): Flt1 expression was strong in all placentas with untreated infection (109.9). In the HIG treatment group, the mean level of Flt1 staining intensity was 91.7. Control placentas had the lowest levels (75.6). All infected placentas, untreated $(P<0.001)$ and HIG-treated $(P=0.03)$, showed significantly enhanced levels of Flt1 expression. Notably, Flt1 expression declined significantly after $\mathrm{HIG}$ treatment compared with that for untreated infected placentas $(P=$ 0.024). Taken together, the results indicate that term placentas from women with congenital HCMV infection strongly up-regulate VEGF and Flt1, suggesting a prolonged hypoxic environment. Reduced expression of Flt1 with a marginal reduction in VEGF after HIG treatment suggests a shift from an antiangiogenic to an angiogenic state, thus accelerating compensatory development.

\section{Dysregulated Angiogenic Factors in Amniotic Fluid of Congenitally Infected Fetuses}

Amniotic fluid is composed of substances undergoing bidirectional diffusion from fetal circulation before keratinization of skin, as well as the surface of the amnion, placenta, and umbilical cord. ${ }^{43}$ Having found strong immunostaining of VEGF and Flt1 in cytotrophoblasts (Figures 5-7) and foci of viral replication in placentas from untreated infection (Figure 1), we considered that amniotic fluid could contain dysregulated angiogenic factors resulting from $\mathrm{HCMV}$-infected cells ${ }^{44,45}$ and possible placental hypoxia. ${ }^{46,47}$

A physiological balance between proangiogenic (VEGF/ PIGF) and antiangiogenic (sFlt1) factors that control normal placental development is reflected by sFIt1/PIGF ratios. ${ }^{35}$ sFlt derived from the placenta forms complexes with VEGF and PIGF, reducing their functions. ${ }^{48-50}$

Next, we measured VEGF, PIGF, and sFIt1 in amniotic fluid from 38 cases of untreated congenital HCMV infection, 9 cases from the HIG treatment group, and 7 controls. Amniotic fluid from fetuses with untreated infection contained dramatically elevated levels of sFlt1 (10.1 to $243.7 \mathrm{ng} / \mathrm{ml}$ ) (Figure 8A); sFlt1 values were substantially lower in amniotic fluid from the HIG treatment group (1.1 to $44.5 \mathrm{ng} / \mathrm{ml}$ ), and values were lowest in controls (1.1 to $7.1 \mathrm{ng} / \mathrm{ml}$ ). PIGF levels in amniotic fluid varied in untreated infection (30 to $257 \mathrm{pg} / \mathrm{ml}$ ), HIG treatment (45 to $148 \mathrm{pg} / \mathrm{ml}$ ), and control (82 to $281 \mathrm{pg} / \mathrm{ml}$ ) groups (Figure $8 B$ ). VEGF was not detected (data not shown). Given the high variability of sFlt1 and PIGF within the groups, we reasoned that the ratio of sFlt1/PIGF ratio would be a more reliable index of the status of angiogenic factors in amniotic fluid. Amniotic fluid from untreated infection and from the HIG treatment group contained significantly elevated sFIt1/PIGF ratios compared with controls $(P<$ 0.001 ) (Figure 8C). Although the mean sFlt1/PIGF ratio in the HIG treatment group decreased compared with that in the untreated infection group, the differences were not significant $(P=0.135)$.

Next, we determined whether sFt1/PIGF ratios in amniotic fluid could predict poor fetal outcome, including temporary symptoms that resolve soon after birth (IUGR 

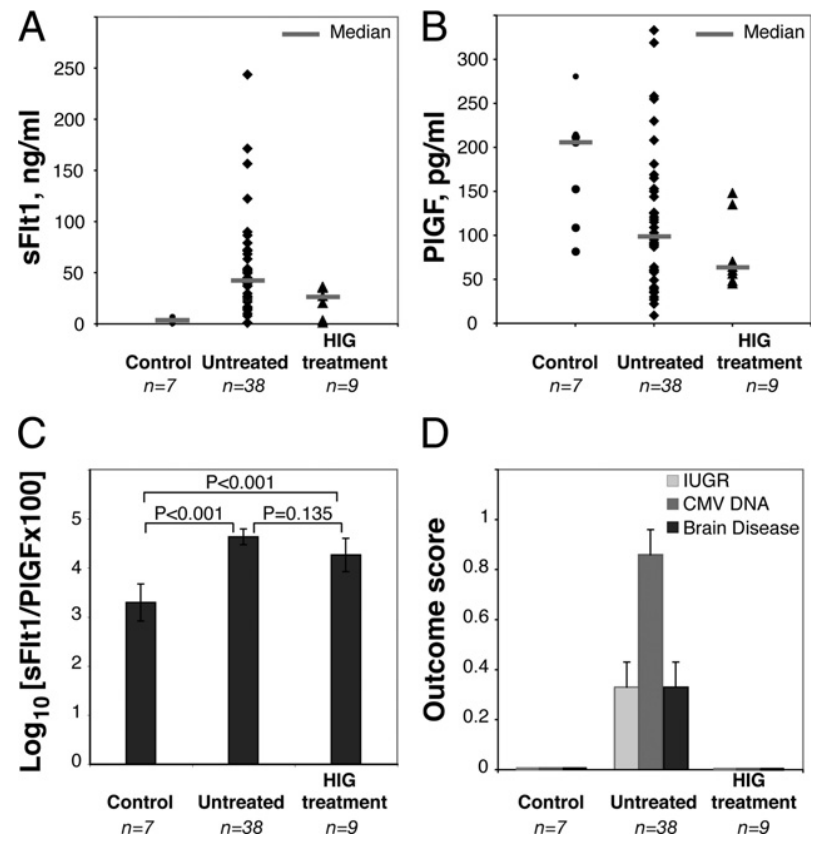

D

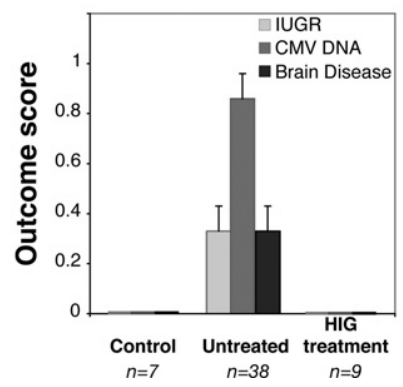

Figure 8. Increase in sFlt1/PlGF ratios in amniotic fluid from women with untreated congenital HCMV infection associated with poor outcome score Values of sFlt1 (A), PlGF (B), and the mean sFlt1/PlGF ratio after logarithmic transformation $(\mathbf{C})$ in uninfected control $(n=7)$, untreated congenital infection $(n=38)$, and HIG treatment $(n=9)$ groups. A and B: Median values of each set of data points are indicated by a horizontal bar C: Results are expressed as mean \pm SEM and compared between groups using Bonferron correction of $P$ values for multiple comparisons. Differences were significant between untreated infection and control groups $(P<0.001)$ and between HIG treatment and control groups $(P<0.001)$ but not between untreated infection and HIG treatment groups $(P=0.135)$. D: Fetal outcomes in control, untreated infection, and HIG treatment groups were scored as 0 for no symptoms and 1 for symptoms (IUGR, HCMV DNA in urine at birth, or brain disease). The outcome score is expressed as mean \pm SEM.

and hepatosplenomegaly) and permanent birth defects (neurological impairment). ${ }^{12}$ Each clinical manifestation associated with congenital infection-IUGR, fetal infection (CMV DNA positive) and brain disease-was scored as 1. Absence of a symptom was scored as 0. A comparison of fetal symptoms at birth ("outcome score") (Figure $8 \mathrm{D}$ ) and sFlt1/PIGF ratios (Figure $8 \mathrm{C}$ ) showed that amniotic fluid from symptomatic babies with untreated congenital infection had significantly elevated sFlt1/PIGF ratios compared with controls $(P<0.001)$. In addition, the sFIt1/PIGF ratios in the asymptomatic infection with HIG treatment group were significantly higher than those in controls $(P<0.001)$. The decrease in the ratio between the untreated infection and HIG treatment groups was not significant $(P=0.135)$ and may be due to the small sample size. Taken together, the results suggest that an elevated sFIt1/PIGF ratio in amniotic fluid could indicate a hypoxia-like environment in congenital HCMV infection.

\section{Discussion}

In this study, we showed that a hypoxia-like condition in placentas congenitally infected with HCMV up-regulates VEGF expression and, combined with HIG treatment, promotes compensatory development, increasing the number of chorionic villi and the vasculature that im- proves fetal outcome. Previous studies of early-gestation placentas infected with HCMV revealed virus replication in uterine and fetal blood vessels, villous cytotrophoblast progenitors, and differentiating cells. ${ }^{19,20,22,25}$ Others found HCMV antigens in trophoblasts, stromal cells, and endothelial cells of placentas from symptomatic congenital infection. ${ }^{51,52}$ We reported that HCMV infects the decidua and spreads to the placenta. ${ }^{23}$ Infected cells include endothelial cells of the uterine vasculature, ${ }^{21}$ invasive cytotrophoblasts, ${ }^{19}$ and decidual cells and uterine glandular epithelial cells. ${ }^{20}$ Infected cytotrophoblasts invading the decidua could impair differentiation/invasion through a constellation of events ${ }^{19,26,27,53}$ that compromise cytotrophoblast remodeling of uterine arteries, diminish maternal blood flow, and contribute to a hypoxialike condition. We found infected uterine arteries with intramural fibrinoids and vasculitis of blood vessels in the villous core that could lead to thrombosis and calcification, ${ }^{36}$ reducing blood return and resulting in placental edema. Extremely thick placentas with microcalcifications and focal ischemia have been reported in cases of severe congenital infection. ${ }^{29,54-57}$ Because the placenta lacks a lymphatic system, ${ }^{58}$ reduced blood flow could cause hydropic villi and, in severe cases of congenital infection, fetal hydrops. ${ }^{57,59,60}$

Some temporary symptoms of congenital HCMV infection, such as thrombocytopenia, extramedullary hematopoiesis (blueberry muffin syndrome), and hepatomegaly, are probably fetal compensation for hypoxia. ${ }^{61-64}$ The reversible nature of these symptoms was shown by treatment of congenital infection with HCMV-specific HIG. ${ }^{28,65-67}$ In contrast, sensorineural hearing loss correlates with symptomatic congenital infection at birth and prolonged virus shedding. ${ }^{68,69}$ Together, the transient clinical manifestations could result from reduced nutrient and oxygen transport to the fetus, whereas permanent neurological damage could be caused by both HCMV replication in fetal brain and hypoxic conditions in utero. Infection-induced damage could lead to hypoxia-like conditions and associated compensatory development (substantially increased numbers of chorionic villi and capillaries) in placentas with HIG treatment. HCMV infection in the uterine vasculature (decidua) results in fibrinoids (thrombi), spreads to cytotrophoblasts, and impairs invasiveness that together reduce maternal blood flow. Viral replication in cytotrophoblasts, endothelium, and stromal fibroblasts results in fibrosis from deposition of extracellular matrix proteins by integrin $\alpha \vee \beta 6$-mediated transforming growth factor- $\beta$ activation ${ }^{27}$ and impairment of extracellular matrix degradation by down-regulation of matrix metalloproteinase activity. ${ }^{26}$ Eventually, transport of nutrients and oxygen to the fetal compartment would be impaired. As fetal demands for oxygen increase, the intrauterine environment becomes hypoxic, and adaptation takes the form of dilated blood vessels congested with fetal leukocytes and erythrocytes. In hydropic villi, capillaries were located at the villous periphery, close to syncytiotrophoblasts to optimize transport to the fetal bloodstream (Figures 2, E and F, and 4B). Such vascular changes were not observed in placentas with HIG treatment, in which capillaries were distributed throughout the 
villus core of many immature villi (Figure 4D). Importantly, the overall surface for exchange between the maternal and fetal circulation was dramatically increased with HIG treatment in early gestation, a time when the abundant cytotrophoblast stem cell population enables plasticity and remodeling of chorionic villi. It follows that a greater syncytiotrophoblast surface area and microvascular mass will increase blood flow and improve the efficiency of oxygen, nutrient, and IgG transport from the maternal to fetal circulation.

Others reported that placentas with symptomatic congenital HCMV infection contain more immature villi. ${ }^{70}$ Quantitative analysis showed that the number of chorionic villi significantly increased with HIG treatment relative to those of controls, but untreated infection had only marginal increases (Figure 3D). Under hypoxic conditions in first-trimester placentas, villous cytotrophoblasts proliferate, differentiate, and invade the uterine wall, regulated by oxygen tension. ${ }^{71}$ When a hypoxic environment persists, cytotrophoblast stem cells divide and form new villi. Our results suggest that a prolonged hypoxia-like state associated with congenital infection could extend this process. In pregnant women from high altitudes with low oxygen, the relative volume of cytotrophoblasts increases $^{37}$ and placentas weigh significantly more than they do at sea level, suggesting adaptation by development of a more extensive peripheral villous tree. ${ }^{72}$ Placental weights also increase in heavy smokers, ${ }^{73}$ but the cytotrophoblast stem cell population is prematurely depleted and the number of anchoring villi is reduced..$^{74}$ In addition, capillary densities increase within placental terminal convolutes, suggesting an adaptive angiogenic response in chorionic villi. ${ }^{39}$ Placentas with congenital HCMV infection increase in weight and thickness, and HIG treatment leads to some reduction in size, ${ }^{29}$ suggesting that irreversible enlargement could result from a combined increase in the numbers of chorionic villi and villous capillaries. Like quiescent endothelium, ${ }^{75,76}$ blood vessels in control placentas expressed CD34 but those in untreated and HIG-treated placentas failed to express CD34 or did so weakly, suggesting a proliferating endothelium.

Balanced VEGF and PIGF levels throughout gestation are necessary for normal placental development. In the first trimester, physiological hypoxia favors VEGF expression, which influences branching angiogenesis. ${ }^{36}$ In the third trimester, normal oxygen levels correlate with strong PIGF expression and nonbranching angiogenesis, whereas VEGF levels decline. ${ }^{77-79}$ Cytotrophoblasts cultured under hypoxic conditions strongly up-regulate VEGF expression and down-regulate PIGF. ${ }^{80}$ VEGF expression is dramatically up-regulated in placentas from women who smoke during gestation and enormously enlarged blood vessels develop at the periphery of villi. ${ }^{38,81}$ In parallel with increased numbers of immature villi (Figure 3 ) and blood vessels (Figure 4), VEGF expression was significantly upregulated in syncytiotrophoblasts, cytotrophoblasts, and blood vessels of infected placentas, with or without HIG treatment, relative to controls (Figure 7). Taken together, the results suggest that induced VEGF expression could contribute to the adaptation found in congenitally infected pla- centas. Quantitative analysis strongly suggests that the compensatory development was a response to biologically active VEGF up-regulated by a hypoxia-like condition from viral damage at the uterine-placental interface. It is also possible that VEGF expression was up-regulated by the inflammatory cytokines, TNF- $\alpha$ and interleukin-6, ${ }^{82-84}$ associated with HCMV replication, ${ }^{85,86}$ especially considering the higher levels of VEGF that were found in untreated congenital infection. VEGF expression could also be a downstream effect of hypoxia-inducible factor $1 \alpha$ induction by activation of a nuclear receptor, peroxisome proliferatoractivated receptor $\gamma(\text { PPAR } \gamma)^{87}$ that modulates cytotrophoblast differentiation/invasion. ${ }^{88,89} \mathrm{HCMV}$-infected cytotrophoblasts induce transcriptional activity of PPAR $\gamma$ that binds to the viral immediate-early promotor, resulting in enhanced replication and reduced cell invasion. ${ }^{90}$ In mononuclear phagocytes, PPAR $\gamma$ activation trans-represses the metalloproteinase 9 promoter. ${ }^{91}$ Whether downstream effects of HCMV-induced PPAR $\gamma$ activation in cytotrophoblasts also reduce metalloproteinase 9 protein that degrades the extracellular matrix ${ }^{26}$ contributing to reduced cell functions ${ }^{53}$ remains to be tested.

Placental development is regulated by levels of proand antiangiogenic factors reflected in sFIt $1 / P I G F$ ratios. ${ }^{35}$ In amniotic fluid, sFlt1 forms complexes with VEGF and PIGF that could reduce free, functional angiogenic factors. ${ }^{48}$ In healthy pregnancies, increased sFlt1 levels positively correlate with PIGF levels, whereas in preeclampsia they have a negative correlation. ${ }^{46,92-94}$ Interestingly, in a case of severe congenital HCMV infection with mirror syndrome, maternal symptoms that resemble preeclampsia, sFlt1 levels in serum increased precipitously. ${ }^{57}$ We found sFlt1/PIGF ratios to be significantly elevated in amniotic fluid from untreated congenital infection and $H I G$ treatment compared with controls (Figure $8 \mathrm{C}$ ). Moreover, sFIt1/PIGF ratios tended to decrease in the HIG treatment group relative to those in the untreated infection group. Angiogenic factors and antagonists are dysregulated in various pregnancy complications involving the placenta. Our studies suggest that congenital HCMV infection could induce a hypoxic state and compensatory development similar to that in pregnancies at high altitude ${ }^{37}$ and when the mother smoked during gestation. ${ }^{38}$ In preeclampsia, sFlt1 is elevated and PIGF is reduced in the maternal circulation ${ }^{92-95}$ and amniotic fluid. ${ }^{46}$ VEGF expression is reduced in cytotrophoblasts cultured from these placentas, ${ }^{16}$ which could explain the failure of preeclamptic placentas to undergo compensation found in smokers. ${ }^{81}$

Our results suggest that $H I G$ treatment reduced viral replication in the placenta and subsequent injury from persistent infection. As reported, significantly fewer babies had congenital infection or disease after HIG treatment. ${ }^{28}$ In vitro, HIG reduces HCMV infection of fibroblasts, neutralizes virus-induced intracellular NF- $\kappa$ B and phosphatidylinositol 3-kinase signaling pathways, ${ }^{96}$ and has neutralizing activity that blocks virus entry into epithelial cells. ${ }^{97} \mathrm{HIG}$ treatment is associated with increased HCMV-specific IgG concentration and avidity in maternal circulation after infusion. ${ }^{28}$ At delivery, IgG avidity in placentas with treatment is higher than that in those with 
untreated infection and provides an immediate source of protective antibodies that evolved over the course of gestation. A recent study of placentas from uncomplicated deliveries in seropositive women showed that the concentration of high-avidity, HCMV-specific IgG with virus-neutralizing activity in the fetal bloodstream is equal to or higher than the concentration in the maternal circulation. ${ }^{98}$ Thus, antibodies from HIG infusions could first reach the placenta, suppress viral replication, and eventually reach the fetal bloodstream, facilitated by neonatal Fc receptor transcytosis across syncytiotrophoblasts. ${ }^{99,100}$ High-avidity, HCMV-specific antibodies could prevent viral transmission 20,22 and fetal infection or symptomatic disease. ${ }^{28,101,102}$ Administration of HIG after maternal seroconversion in early gestation, when cytotrophoblasts proliferate, could reduce viral injury and accelerate and prolong development to compensate for hypoxia-like conditions. Together with serological evidence of primary maternal infection, our findings suggest that an elevated sFlt1/PIGF ratio precedes fetal transmission and the presence of HCMV DNA in amniotic fluid. Accordingly, these proteins could serve as early biomarkers of placental infection to identify at-risk pregnancies that could benefit from HIG treatment to prevent infection and congenital disease.

\section{Acknowledgments}

We thank Yan Zhou and Grace Kim for guidance with histopathology, Olga Genbacev for valuable scientific discussions, June Fang-Hoover for technical support, and Mary McKenney for editing the manuscript.

\section{References}

1. Kenneson A, Cannon MJ: Review and meta-analysis of the epidemiology of congenital cytomegalovirus (CMV) infection. Rev Med Virol 2007, 17:253-276

2. Colugnati FA, Staras SA, Dollard SC, Cannon MJ: Incidence of cytomegalovirus infection among the general population and pregnant women in the United States. BMC Infect Dis 2007, 7:71

3. Cannon MJ, Pellett PE: Risk of congenital cytomegalovirus infection. Clin Infect Dis 2005, 40:1701-1702; author reply 1702-1703

4. Demmler GJ: Congenital cytomegalovirus infection and disease. Adv Pediatr Infect Dis 1996, 11:135-162

5. Pass RF, Fowler KB, Boppana SB, Britt WJ, Stagno S: Congenital cytomegalovirus infection following first trimester maternal infection: symptoms at birth and outcome. J Clin Virol 2006, 216-220

6. Fowler KB, Stagno S, Pass RF: Maternal immunity and prevention of congenital cytomegalovirus infection. JAMA 2003, 289:1008-1011

7. Pass BF: Cytomegalovirus. Edited by Knipe DM, Howley PM. New York, Lippincott-Raven, 2001, pp 2675-2705

8. Stagno S, Pass RF, Cloud G, Britt WJ, Henderson RE, Walton PD, Veren DA, Page F, Alford CA: Primary cytomegalovirus infection in pregnancy. Incidence, transmission to fetus, and clinical outcome. JAMA 1986, 256:1904-1908

9. Revello MG, Gerna G: Pathogenesis and prenatal diagnosis of human cytomegalovirus infection. J Clin Virol 2004, 29:71-83

10. Revello MG, Zavattoni M, Furione M, Lilleri D, Gorini G, Gerna G: Diagnosis and outcome of preconceptional and periconceptional primary human cytomegalovirus infections. J Infect Dis 2002, 186:553-557

11. Bodéus M, Kabamba-Mukadi B, Zech F, Hubinont C, Bernard P, Goubau P: Human cytomegalovirus in utero transmission: follow-up of 524 maternal seroconversions. J Clin Virol 2010, 47:201-202

12. Noyola DE, Demmler GJ, Nelson CT, Griesser C, Williamson WD,
Atkins JT, Rozelle J, Turcich M, Llorente AM, Sellers-Vinson S, Reynolds A, Bale JF Jr, Gerson P, Yow MD: Early predictors of neurodevelopmental outcome in symptomatic congenital cytomegalovirus infection. J Pediatr 2001, 138:325-331

13. Norwitz ER, Schust DJ, Fisher SJ: Implantation and the survival of early pregnancy. N Engl J Med 2001, 345:1400-1408

14. Genbacev O, Zhou Y, Ludlow JW, Fisher SJ: Regulation of human placental development by oxygen tension. Science 1997, 277:1669-1672

15. Genbacev O, Krtolica A, Kaelin W, Fisher SJ: Human cytotrophoblast expression of the von Hippel-Lindau protein is downregulated during uterine invasion in situ and upregulated by hypoxia in vitro. Dev Biol 2001, 233:526-536

16. Zhou Y, McMaster M, Woo K, Janatpour M, Perry J, Karpanen T, Alitalo K, Damsky C, Fisher SJ: Vascular endothelial growth factor ligands and receptors that regulate human cytotrophoblast survival are dysregulated in severe preeclampsia and hemolysis, elevated liver enzymes, and low platelets syndrome. Am J Pathol 2002, 160:1405-1423

17. Zhou Y, Bellingard V, Feng KT, McMaster M, Fisher SJ: Human cytotrophoblasts promote endothelial survival and vascular remodeling through secretion of Ang2. PIGF, and VEGF-C. Dev Biol 2003, 263:114-125

18. Janatpour MJ, Utset MF, Cross JC, Rossant J, Dong J, Israel MA, Fisher SJ: A repertoire of differentially expressed transcription factors that offers insight into mechanisms of human cytotrophoblast differentiation. Dev Genet 1999, 25:146-157

19. Fisher S, Genbacev O, Maidji E, Pereira L: Human cytomegalovirus infection of placental cytotrophoblasts in vitro and in utero: implications for transmission and pathogenesis. J Virol 2000, 74:68086820

20. Pereira L, Maidji E, McDonagh S, Genbacev O, Fisher S: Human cytomegalovirus transmission from the uterus to the placenta correlates with the presence of pathogenic bacteria and maternal immunity. J Virol 2003, 77:13301-13314

21. Maidji E, Percivalle E, Gerna G, Fisher S, Pereira L: Transmission of human cytomegalovirus from infected uterine microvascular endothelial cells to differentiating/invasive placental cytotrophoblasts. Virology 2002, 304:53-69

22. Maidji E, McDonagh S, Genbacev O, Tabata T, Pereira L: Maternal antibodies enhance or prevent cytomegalovirus infection in the placenta by neonatal Fc receptor-mediated transcytosis. Am J Pathol 2006, 168:1210-1226

23. McDonagh S, Maidji E, Ma W, Chang HT, Fisher S, Pereira L: Viral and bacterial pathogens at the maternal-fetal interface. J Infect Dis 2004, 190:826-834

24. McDonagh S, Maidji E, Chang H-T, Pereira L: Patterns of human cytomegalovirus infection in term placentas: a preliminary analysis. J Clin Virol 2006, 35:210-215

25. Maidji E, Genbacev O, Chang HT, Pereira L: Developmental regulation of human cytomegalovirus receptors in cytotrophoblasts correlates with distinct replication sites in the placenta. J Virol 2007, 81:4701-4712

26. Yamamoto-Tabata T, McDonagh S, Chang H-T, Fisher S, Pereira L: Human cytomegalovirus interleukin-10 downregulates matrix metalloproteinase activity and impairs endothelial cell migration and placental cytotrophoblast invasiveness in vitro. J Virol 2004, 78:2831-2840

27. Tabata T, Kawakatsu H, Maidji E, Sakai T, Sakai K, Fang-Hoover J, Aiba M, Sheppard D, Pereira L: Induction of an epithelial integrin $\alpha \vee \beta 6$ in human cytomegalovirus-infected endothelial cells leads to activation of transforming growth factor- $\beta 1$ and increased collagen production. Am J Pathol 2008, 172:1127-1140

28. Nigro G, Adler SP, La Torre R, Best AM: Passive immunization during pregnancy for congenital cytomegalovirus infection. $N$ Engl J Med 2005, 353:1350-1362

29. La Torre R, Nigro G, Mazzocco M, Best AM, Adler SP: Placental enlargement in women with primary maternal cytomegalovirus infection is associated with fetal and neonatal disease. Clin Infect Dis 2006, 43:994-1000

30. Nigro G, La Torre R, Anceschi MM, Mazzocco M, Cosmi EV Hyperimmunoglobulin therapy for a twin fetus with cytomegalovirus infection and growth restriction. Am J Obstet Gynecol 1999, 180:1222-1226 
31. Leal S, Diniz C, Sa C, Goncalves J, Soares AS, Rocha-Pereira C Fresco P: Semiautomated computer-assisted image analysis to quantify $3,3^{\prime}$-diaminobenzidine tetrahydrochloride-immunostained small tissues. Anal Biochem 2006, 357:137-143

32. Allen MV, Smith GJ, Juliano R, Maygarden SJ, Mohler JL: Downregulation of the $\beta 4$ integrin subunit in prostatic carcinoma and prostatic intraepithelial neoplasia. Hum Pathol 1998, 29:311-318

33. Cullen JJ, Mitros FA, Oberley LW: Expression of antioxidant enzymes in diseases of the human pancreas: another link between chronic pancreatitis and pancreatic cancer. Pancreas 2003, 26:23-27

34. Buhimschi CS, Norwitz ER, Funai E, Richman S, Guller S, Lockwood $\mathrm{CJ}$, Buhimschi IA: Urinary angiogenic factors cluster hypertensive disorders and identify women with severe preeclampsia. Am J Obstet Gynecol 2005, 192:734-741

35. Levine RJ, Thadhani R, Qian C, Lam C, Lim KH, Yu KF, Blink AL, Sachs BP, Epstein FH, Sibai BM, Sukhatme VP, Karumanchi SA: Urinary placental growth factor and risk of preeclampsia. JAMA 2005, 293:77-85

36. Benirschke K, Kaufmann P: Pathology of the Human Placenta. Edited by Benirschke K, Kaufmann P. New York, Springer, 2000, pp. 616-636

37. Mayhew TM, Bowles C, Yucel F: Hypobaric hypoxia and villous trophoblast: evidence that human pregnancy at high altitude (3600 $\mathrm{m}$ ) perturbs epithelial turnover and coagulation-fibrinolysis in the intervillous space. Placenta 2002, 23:154-162

38. Genbacev O, McMaster MT, Zdravkovic T, Fisher SJ: Disruption of oxygen-regulated responses underlies pathological changes in the placentas of women who smoke or who are passively exposed to smoke during pregnancy. Reprod Toxicol 2003, 17:509-518

39. Pfarrer C, Macara L, Leiser R, Kingdom J: Adaptive angiogenesis in placentas of heavy smokers. Lancet 1999, 354:303

40. Pusztaszeri MP, Seelentag W, Bosman FT: Immunohistochemical expression of endothelial markers CD31, CD34, von Willebrand factor, and Fli-1 in normal human tissues. J Histochem Cytochem 2006, 54:385-395

41. Forsythe JA, Jiang BH, lyer NV, Agani F, Leung SW, Koos RD, Semenza GL: Activation of vascular endothelial growth factor gene transcription by hypoxia-inducible factor 1. Mol Cell Biol 1996 16:4604-4613

42. Shweiki D, Itin A, Soffer D, Keshet E: Vascular endothelial growth factor induced by hypoxia may mediate hypoxia-initiated angiogenesis. Nature 1992, 359:843-845

43. Underwood MA, Gilbert WM, Sherman MP: Amniotic fluid: not just fetal urine anymore. J Perinatol 2005, 25:341-348

44. Reinhardt B, Schaarschmidt P, Bossert A, Luske A, Finkenzeller G, Mertens $T$, Michel $D$ : Upregulation of functionally active vascular endothelial growth factor by human cytomegalovirus. J Gen Virol 2005, 86:23-30

45. Dumortier J, Streblow DN, Moses AV, Jacobs JM, Kreklywich CN Camp D, Smith RD, Orloff SL, Nelson JA: Human cytomegalovirus secretome contains factors that induce angiogenesis and wound healing. J Virol 2008, 82:6524-6535

46. Vuorela P, Helske S, Hornig C, Alitalo K, Weich H, Halmesmaki E: Amniotic fluid-soluble vascular endothelial growth factor receptor-1 in preeclampsia. Obstet Gynecol 2000, 95:353-357

47. Makrydimas G, Sotiriadis A, Savvidou MD, Spencer K, Nicolaides $\mathrm{KH}$ : Physiological distribution of placental growth factor and soluble Flt-1 in early pregnancy. Prenat Diagn 2008, 28:175-179

48. Hornig C, Barleon B, Ahmad S, Vuorela P, Ahmed A, Weich HA Release and complex formation of soluble VEGFR-1 from endothelial cells and biological fluids. Lab Invest 2000, 80:443-454

49. Clark DE, Smith SK, He Y, Day KA, Licence DR, Corps AN, Lammoglia R, Charnock-Jones DS: A vascular endothelial growth factor antagonist is produced by the human placenta and released into the maternal circulation. Biol Reprod 1998, 59:1540-1548

50. Banks RE, Forbes MA, Searles J, Pappin D, Canas B, Rahman D, Kaufmann S, Walters CE, Jackson A, Eves P, Linton G, Keen J, Walker JJ, Selby PJ: Evidence for the existence of a novel pregnancy-associated soluble variant of the vascular endothelial growth factor receptor, Flt-1. Mol Hum Reprod 1998, 4:377-386

51. Sinzger C, Müntefering H, Löning T, Stöss H, Plachter B, Jahn G: Cell types infected in human cytomegalovirus placentitis identified by immunohistochemical double staining. Virchows Archiv A Pathol Anat Histopathol 1993, 423:249-256

52. Mühlemann K, Miller RK, Metlay L, Menegus MA: Cytomegalovirus infection of the human placenta: an immunocytochemical study. Hum Pathol 1992, 23:1234-1237

53. Tabata T, McDonagh S, Kawakatsu H, Pereira L: Cytotrophoblasts infected with a pathogenic human cytomegalovirus strain dysregulate cell-matrix and cell-cell adhesion molecules: a quantitative analysis. Placenta 2007, 28:527-537

54. Beksaç MS, Saygan-Karamursel B, Ustacelebi S, Altinok G, Dalva K Erdinc S, Balci S: Prenatal diagnosis of intrauterine cytomegalovirus infection in a fetus with non-immune hydrops fetalis. Acta Obstet Gynecol Scand 2001, 80:762-765

55. Inoue T, Matsumura N, Fukuoka M, Sagawa N, Fujii S: Severe congenital cytomegalovirus infection with fetal hydrops in a cytomegalovirus-seropositive healthy woman. Eur J Obstet Gynecol Reprod Biol 2001, 95:184-186

56. Sampath V, Narendran V, Donovan EF, Stanek J, Schleiss MR Nonimmune hydrops fetalis and fulminant fatal disease due to congenital cytomegalovirus infection in a premature infant. J Perinato 2005, 25:608-611

57. Rana S, Venkatesha S, DePaepe M, Chien E, Paglia M, Karumanchi SA: Cytomegalovirus-induced mirror syndrome associated with elevated levels of circulating antiangiogenic factors. Obstet Gynecol 2007, 109:549-552

58. Red-Horse K, Rivera J, Schanz A, Zhou Y, Winn V, Kapidzic M Maltepe E, Okazaki K, Kochman R, Vo KC, Giudice L, Erlebacher A, McCune JM, Stoddart CA, Fisher SJ: Cytotrophoblast induction of arterial apoptosis and lymphangiogenesis in an in vivo model of human placentation. J Clin Invest 2006, 116:2643-2652

59. Hutchison AA, Drew JH, Yu VY, Williams ML, Fortune DW, Beischer NA: Nonimmunologic hydrops fetalis: a review of 61 cases. Obstet Gynecol 1982, 59:347-352

60. Barron SD, Pass RF: Infectious causes of hydrops fetalis. Semin Perinatol 1995, 19:493-501

61. Adler SP, Nigro G, Pereira L: Recent advances in the prevention and treatment of congenital cytomegalovirus infections. Semin Perinatol 2007, 31:10-18

62. Roberts I, Murray NA: Neonatal thrombocytopenia: causes and management. Arch Dis Child Fetal Neonatal Ed 2003, 88:F359-F364

63. Rees S, Inder T: Fetal and neonatal origins of altered brain development. Early Hum Dev 2005, 81:753-761

64. Hödl S, Aubock L, Reiterer F, Soyer HP, Muller WD: Blueberry muffin baby: the pathogenesis of cutaneous extramedullary hematopoiesis. Hautarzt 2001, 52:1035-1042

65. Negishi H, Yamada H, Hirayama E, Okuyama K, Sagawa T, Matsumoto Y, Fujimoto S: Intraperitoneal administration of cytomegalovirus hyperimmunoglobulin to the cytomegalovirus-infected fetus. J Perinatol 1998 18:466-469

66. Nigro G, Torre RL, Pentimalli H, Taverna P, Lituania M, de Tejada BM, Adler SP: Regression of fetal cerebral abnormalities by primary cytomegalovirus infection following hyperimmunoglobulin therapy. Prenat Diagn 2008, 28:512-517

67. Moxley K, Knudtson EJ: Resolution of hydrops secondary to cytomegalovirus after maternal and fetal treatment with human cytomegalovirus hyperimmune globulin. Obstet Gynecol 2008, 111:524-526

68. Bradford RD, Cloud G, Lakeman AD, Boppana S, Kimberlin DW, Jacobs R, Demmler G, Sanchez P, Britt W, Soong SJ, Whitley RJ: Detection of cytomegalovirus (CMV) DNA by polymerase chain reaction is associated with hearing loss in newborns with symptomatic congenital CMV infection involving the central nervous system. J Infect Dis 2005, 191:227-233

69. Rosenthal LS, Fowler KB, Boppana SB, Britt WJ, Pass RF, Schmid SD, Stagno S, Cannon MJ: Cytomegalovirus shedding and delayed sensorineural hearing loss: results from longitudinal follow-up of children with congenital infection. Pediatr Infect Dis J 2009, 28:515-520

70. Garcia AG, Fonseca EF, Marques RL, Lobato YY: Placental morphology in cytomegalovirus infection. Placenta 1989, 10:1-18

71. Genbacev O, Joslin R, Damsky CH, Polliotti BM, Fisher SJ: Hypoxia alters early gestation human cytotrophoblast differentiation/invasion in vitro and models the placental defects that occur in preeclampsia. J Clin Invest 1996, 97:540-550 
72. Krüger $\mathrm{H}$, Arias-Stella J: The placenta and the newborn infant at high altitudes. Am J Obstet Gynecol 1970, 106:586-591

73. Williams LA, Evans SF, Newnham JP: Prospective cohort study of factors influencing the relative weights of the placenta and the newborn infant. BMJ 1997, 314:1864-1868

74. Genbacev O, McMaster MT, Lazic J, Nedeljkovic S, Cvetkovic M, Joslin R, Fisher SJ: Concordant in situ and in vitro data show that maternal cigarette smoking negatively regulates placental cytotrophoblast passage through the cell cycle. Reprod Toxicol 2000, 14:495-506

75. Fina L, Molgaard HV, Robertson D, Bradley NJ, Monaghan P, Delia D, Sutherland DR, Baker MA, Greaves MF: Expression of the CD34 gene in vascular endothelial cells. Blood 1990, 75:2417-2426

76. Schlingemann RO, Rietveld FJ, de Waal RM, Bradley NJ, Skene Al, Davies AJ, Greaves MF, Denekamp J, Ruiter DJ: Leukocyte antigen CD34 is expressed by a subset of cultured endothelial cells and on endothelial abluminal microprocesses in the tumor stroma. Lab Invest 1990, 62:690-696

77. Jackson MR, Carney EW, Lye SJ, Ritchie JW: Localization of two angiogenic growth factors (PDECGF and VEGF) in human placentae throughout gestation. Placenta 1994, 15:341-353

78. Cooper JC, Sharkey AM, Charnock-Jones DS, Palmer CR, Smith SK: VEGF mRNA levels in placentae from pregnancies complicated by pre-eclampsia. Br J Obstet Gynaecol 1996, 103:1191-1196

79. Shiraishi S, Nakagawa K, Kinukawa N, Nakano H, Sueishi K: Immunohistochemical localization of vascular endothelial growth factor in the human placenta. Placenta 1996, 17:111-121

80. Shore VH, Wang TH, Wang CL, Torry RJ, Caudle MR, Torry DS: Vascular endothelial growth factor, placenta growth factor and their receptors in isolated human trophoblast. Placenta 1997, 18:657-665

81. Zdravkovic T, Genbacev O, McMaster MT, Fisher SJ: The adverse effects of maternal smoking on the human placenta: A review. Placenta 2005, 26(Suppl):S81-S86

82. Jiang $H$, Zhu YS, Xu H, Sun Y, Li QF: Inflammatory stimulation and hypoxia cooperatively activate HIF-1 $\alpha$ in bronchial epithelial cells: involvement of PI3K and NF- $\kappa$ B. Am J Physiol Lung Cell Mol Physiol 2010, 298:L660-L669

83. Kuo HP, Lee DF, Xia W, Wei Y, Hung MC: TNF $\alpha$ induces HIF-1 $\alpha$ expression through activation of IKK $\beta$. Biochem Biophys Res Commun 2009, 389:640-644

84. Rojas M, Zhang W, Lee DL, Romero MJ, Nguyen DT, Al-Shabrawey M, Tsai NT, Liou GI, Brands MW, Caldwell RW, Caldwell RB: Role of IL-6 in angiotensin II-induced retinal vascular inflammation. Invest Ophthalmol Vis Sci 51:1709-1718

85. Halwachs-Baumann G, Weihrauch G, Gruber HJ, Desoye G, Sinzger C: hCMV induced IL-6 release in trophoblast and trophoblast like cells. J Clin Virol 2006, 37:91-97

86. Smith PD, Saini SS, Raffeld M, Manischewitz JF, Wahl SM: Cytomegalovirus induction of tumor necrosis factor- $\alpha$ by human monocytes and mucosal macrophages. J Clin Invest 1992, 90:1642-1648

87. Zhou J, Zhang W, Liang B, Casimiro MC, Whitaker-Menezes D, Wang M, Lisanti MP, Lanza-Jacoby S, Pestell RG, Wang C: PPAR $\gamma$ activation induces autophagy in breast cancer cells. Int J Biochem Cell Biol 2009, 41:2334-2342

88. Tarrade A, Schoonjans K, Pavan L, Auwerx J, Rochette-Egly C,
Evain-Brion D, Fournier T: PPAR $\gamma /$ RXR $\alpha$ heterodimers control human trophoblast invasion. J Clin Endocrinol Metab 2001, 86:5017-5024

89. Schaiff WT, Carlson MG, Smith SD, Levy R, Nelson DM, Sadovsky Y: Peroxisome proliferator-activated receptor- $\gamma$ modulates differentiation of human trophoblast in a ligand-specific manner. J Clin Endocrinol Metab 2000, 85:3874-3881

90. Rauwel B, Mariame B, Martin H, Nielsen R, Allart S, Pipy B, Mandrup S, Devignes MD, Evain-Brion D, Fournier T, Davrinche C: Activation of peroxisome proliferator-activated receptor $\gamma$ by human cytomegalovirus for de novo replication impairs migration and invasiveness of cytotrophoblasts from early placentas. J Virol 2010, 84:2946-2954

91. Marx N, Sukhova G, Murphy C, Libby P, Plutzky J: Macrophages in human atheroma contain PPAR : differentiation-dependent peroxisomal proliferator-activated receptor $\gamma(\operatorname{PPAR} \gamma)$ expression and reduction of MMP-9 activity through PPAR $\gamma$ activation in mononuclear phagocytes in vitro. Am J Pathol 1998, 153:17-23

92. Maynard SE, Min JY, Merchan J, Lim KH, Li J, Mondal S, Libermann TA, Morgan JP, Sellke FW, Stillman IE, Epstein FH, Sukhatme VP, Karumanchi SA: Excess placental soluble fms-like tyrosine kinase 1 (sFlt1) may contribute to endothelial dysfunction, hypertension, and proteinuria in preeclampsia. J Clin Invest 2003, 111:649-658

93. Levine RJ, Maynard SE, Qian C, Lim KH, England LJ, Yu KF, Schisterman EF, Thadhani R, Sachs BP, Epstein FH, Sibai BM, Sukhatme VP, Karumanchi SA: Circulating angiogenic factors and the risk of preeclampsia. N Engl J Med 2004, 350:672-683

94. Vatten LJ, Eskild A, Nilsen TI, Jeansson S, Jenum PA, Staff AC: Changes in circulating level of angiogenic factors from the first to second trimester as predictors of preeclampsia. Am J Obstet Gynecol 2007, 196:239 e231-e236

95. Maynard SE, Venkatesha S, Thadhani R, Karumanchi SA: Soluble Fms-like tyrosine kinase 1 and endothelial dysfunction in the pathogenesis of preeclampsia. Pediatr Res 2005, 57:1R-7R

96. Andreoni KA, Wang X, Huang SM, Huang ES: Human cytomegalovirus hyperimmune globulin not only neutralizes HCMV infectivity, but also inhibits HCMV-induced intracellular NF- $\kappa \mathrm{B}, \mathrm{Sp} 1$, and PI3-K signaling pathways. J Med Virol 2002, 67:33-40

97. Cui X, Meza BP, Adler SP, McVoy MA: Cytomegalovirus vaccines fail to induce epithelial entry neutralizing antibodies comparable to natural infection. Vaccine 2008, 26:5760-5766

98. Nozawa N, Fang-Hoover J, Tabata T, Maidji E, Pereira L: Cytomegalovirus-specific, high-avidity IgG with neutralizing activity in maternal circulation enriched in the fetal bloodstream. J Clin Virol 2009, 46(Suppl 4):S58-S63

99. Simister NE, Story CM, Chen HL, Hunt JS: An IgG-transporting FC receptor expressed in the syncytiotrophoblast of human placenta. Eur J Immunol 1996, 26:1527-1531

100. Simister NE, Story CM: Human placental Fc receptors and the transmission of antibodies from mother to fetus. J Reprod Immunol 1997, 37:1-23

101. Boppana SB, Britt WJ: Antiviral antibody responses and intrauterine transmission after primary maternal cytomegalovirus infection. J Infect Dis 1995, 171:1115-1121

102. Pass RF, Fowler KB, Boppana SB, Britt WJ, Stagno S: Congenital cytomegalovirus infection following first trimester maternal infection: symptoms at birth and outcome. J Clin Virol 2006, 35:216-220 